\title{
USING AN ASSESSMENT RUBRIC FOR FEEDBACK AND LEARNING: A CONCEPTUAL STUDY
}

\author{
Vidar Gynnild \\ Department of Education and Lifelong Learning, NTNU, Norwegian University of Science and \\ Technology (Norway)
}

\begin{abstract}
Teachers in artistic disciplines have until recently enjoyed high levels of freedom without the use of any strict measurement model recommended in some other disciplines. Assessment and grading have largely drawn on tacit knowledge (Polanyi, 1958; Wenger, 2000) with limited opportunity for students to learn from their experiences. This paper emerged as part of an action research study aimed to establish explicit assessment criteria for grading vocal performances; however, the focus here is on the use of assessment criteria for educational purposes. Ideas emerged through collaboration with eight academy professors who explored the use of a rubric as part of their academy teaching. Assessing vocal performances draws on concepts that students may not be familiar with on entry to the academy; however, linking concepts with phenomena facilitates self-monitored learning processes.
\end{abstract}

Keywords: Assessment rubric, criteria, feedback, learning.

\section{Introduction}

Assessment is at the heart of the student experience, and given its centrality for learning, institutions spend much time and energy to get the process transparent, reliable and valid. In a strict sense, grades represent levels of achievement as documented in artefacts or at exams (Sadler, 2009); however, since this is not the occasion to delve into specific issues of grading, we rather consider the use of rubrics for learning. While vocal education is used as an example, the approach applies for artistic disciplines generally, and the study will therefore be of interest to those with a stake in formative assessment and learning in artistic disciplines. Feedback facilitates learning, and timely comments on students' performances can be an effective means to improve practices.

This study emerged from efforts aimed at developing an assessment rubric in vocal education (Gynnild, 2015). The project team assumed the application of explicit criteria would facilitate the grading process itself, and improve candidates' sense making of grades. There is indeed a long tradition to assess performances without the use of explicit criteria, drawing on experience and tacit knowledge of artistic performances (Polanyi, 1958). Still, the academy professors believed explicit criteria would improve the accuracy of grading by practicing more systematic and rigorous procedures (Kokotsaki, Davidson, \& Coimbra, 2001).

Rubrics are frameworks to structure discussions on the nature and level of intended learning. Technically, rubrics consist of two dimensions, standards and criteria; however, in everyday language these are often termed "criteria". They refer to the nature of intended learning, while standards denote levels of achievement associated criteria. In the project referred to above (Gynnild, 2015), we found it harder to be explicit about standards compared with criteria. In fact, we did not manage to make standards explicit, which complicated the use of the rubric. While professors found it sensible to agree on criteria, grading largely relied on experience and tacit knowledge. Level of achievement would require separate criteria, and the use of them would be rather demanding.

This study argues in favor of criteria to support self-monitored learning. Self-monitored learning is here defined "as being able to understand and to control the doing while it is happening" (Sadler, 1998, p. 1). It ranks as a highly desirable educational goal since it aims to prepare for life-long learning. The process is cyclical, wherein the candidate starts with planning a task followed by monitoring of the process, and finally reflects on the outcome. This cycle is repeatable if the student makes use of his/her reflections to adjust and prepare. However, it is not a one-size-fits-all procedure, and needs to be adapted to context (Zimmerman, 2002). 


\section{Literature and research question}

There is an abundance of studies on assessment across the spectrum of disciplines in higher education. However, studies of assessment and learning in vocal education are rare, probably due the complexity of the research topic, and assessment of vocal performances is complicated compared with instrumental performance evaluation (Wapnick \& Ekholm, 1997). Characteristic features such as diction and transmission of emotional meaning of lyrics are unique to vocal performances, adding to the demands of professional judgment. A study at the Guildhall School of Music in London found that assessment criteria were implicitly rather than explicitly held; however, still with a shared code of judgment in operation (Davidson \& Coimbra, 2001). Interestingly, assessors were not completely sure how their experiences and beliefs lead to a particular decision. Even though agreements on grades may indicate the presence of shared criteria, assessors routinely experience variation in the composition of grades, indicating different judgments of various artistic elements.

A study from France (Maugars, 2006) concluded that explicit criteria were not in use, which in turn prevented formative use of assessment data, since stakeholders possessed no information on criteria. This study examines the use of rubrics for learning purposes in vocal education: What is the learning potential of criteria initially developed for grading purposes? Data was collected rather informally by approaching 7-8 academy professors who volunteered to share their views in response to the research question. The idea of the study emerged on completion of a rubric for grading of vocal performances, as seen in the left column in Figure 1 below:

Table 1. Assessment rubric for vocal performances (from Gynnild, 2015).

\begin{tabular}{|c|c|c|c|c|c|c|c|}
\hline $\begin{array}{l}\text { Grades } \\
\text { Grades converted into numbers }\end{array}$ & $\begin{array}{l}\mathrm{A} \\
5 \\
\end{array}$ & $\begin{array}{l}\mathrm{B} \\
4 \\
\end{array}$ & $\begin{array}{l}\mathrm{C} \\
3 \\
\end{array}$ & $\begin{array}{l}\mathrm{D} \\
2 \\
\end{array}$ & $\begin{array}{l}\mathrm{E} \\
1 \\
\end{array}$ & $\begin{array}{l}\mathrm{F} \\
0 \\
\end{array}$ & \\
\hline 1. Technique & & & & & & & Comments: \\
\hline \multicolumn{8}{|l|}{ Posture, relaxation } \\
\hline \multicolumn{8}{|c|}{ Breathing and support (energy, compression) } \\
\hline \multicolumn{8}{|l|}{ Attack, air flow } \\
\hline \multicolumn{8}{|c|}{ Vocal equalisation (evenness of timbre) } \\
\hline \multicolumn{8}{|l|}{ Intonation } \\
\hline \multicolumn{8}{|l|}{ Equalisation of registers (balance) } \\
\hline \multicolumn{8}{|l|}{ Voice focus } \\
\hline \multicolumn{8}{|l|}{ Vocal range } \\
\hline \multicolumn{8}{|l|}{ Timbre } \\
\hline \multicolumn{8}{|l|}{ Coloratura, trill, ornamentation etc. } \\
\hline 2. Language/text & & & & & & & Comments: \\
\hline \multicolumn{8}{|c|}{$\begin{array}{l}\text { Articulation and textual enunciation (linguistic } \\
\text { precision) }\end{array}$} \\
\hline \multicolumn{8}{|c|}{$\begin{array}{l}\text { Textual interpretation (understanding, } \\
\text { independence and diction) }\end{array}$} \\
\hline \multicolumn{8}{|l|}{ Linguistic breadth (for exam concert) } \\
\hline 3. Musicality & & & & & & & Comments: \\
\hline \multicolumn{8}{|c|}{ Understanding of style (stylistic differentiation) } \\
\hline \multicolumn{8}{|l|}{ Phrasing/ legato } \\
\hline \multicolumn{8}{|l|}{ Dynamics (variation, contrasts) } \\
\hline \multicolumn{8}{|c|}{ Tempo (choice of tempo, stability of tempo) } \\
\hline \multicolumn{8}{|l|}{ Rhythm (steadiness and flexibility) } \\
\hline 4. Ability to communicate & & & & & & & Comments: \\
\hline \multicolumn{8}{|l|}{ Presentation (oral introductions) } \\
\hline \multicolumn{8}{|c|}{ Communication (conviction, charisma, style) } \\
\hline Scenic presentation and staging & & & & & & & \\
\hline
\end{tabular}




\section{Rubrics and self-monitored learning}

Students often enter higher education with the expectation of being taught, rather than engaging actively in learning themselves. Typically, first-year students often feel uneasy about being brought out of their comfort zones as passive learners; however, independent and self-monitored learning is a highly valued skill within and beyond vocal education settings. This motivated the study of the assessment rubric for learning purposes, and a distinction between holistic and analytic rubrics was made. Holistic rubrics provide a single score for the performance. This represents a quick and easy scoring method, but does not provide detailed information on how to improve. This method has a long history in music education, but fails to address particular strengths and weaknesses in order to improve. Contrary to this, analytic rubrics, as in our case, enable feedback along several dimensions including opportunities for students to self-monitor and self-assess own skills development as part of an ongoing learning process.

Engaging in such independent, high quality learning occurs only when there is a material end in view, or when students engage in learning as a self-rewarding experience (Sadler, 1998). The latter requires a power shift from professors to students in the sense that instructors act as facilitators of professional practice rather than transmitters of knowledge. The role of the professor is no longer to be judgmental, but rather to observe, listen, reflect and discuss along with students. This is likely to make interaction with professors less intimidating and more of a rewarding experience. Furthermore, it helps to get students familiar with the level of performance expected prior to final exams and grading.

All too often, summative assessment takes place with little learning as a result, with students unaware of criteria and their implications. The use of an analytic rubric involves the application of criteria to empower students prior to any summative assessment. However, this requires more than the mere exposition of criteria in verbal form. The most important part will be students' sense making of criteria, and their ability to create a coherent artistic performance. At a professional level, the integration of the entire range of criteria is necessary; however, this requires experience and maturity. The focus of this study is on early stages of vocal education, when students are about to familiarize themselves with the artistic vocabulary. The review of criteria, as seen in Table 1, offers an opportunity to get to grips with terms such as posture, attack, equalization, vocal range and textual interpretations. Only when such terms make sense, can students work systematically to improve and refine their performance.

Self-monitoring skills should not be an add-on to programs, but rather an integral part addressed already at the educational design stage, supported by a more even power distribution between students and professors. The purpose is to nurture and strengthen inherent capabilities as lifelong learners by boosting students' self-confidence to facilitate the pursuit of longer-term professional goals: "Students need to be inducted into the process - so they can learn and monitor and control the quality of their own performances and productions while their productions are in progress" (Sadler, 2015).

\section{Discussion}

Modern pedagogy emphasizes the importance of active learning methods. Rather than receiving instructions from an authority, students should engage in activities to give and receive feedback. The centrality of assessment makes it an interesting theme to explore, however, assessment for grading takes skills and experience beyond expectations of novice students. The approach introduced here; however, is formative. It aims to facilitate learning by introducing students to key performance criteria.

Summative and formative assessment refer to different realities. In a criterion-based assessment framework, standards refer to levels of achievement; however, verbal descriptions of absoluteness is hard to achieve. Words used in grade descriptions, such as excellent or outstanding, are comparative, referring to works of others. Attempts at disclosing standards routinely suffer from interpretation bias since we miss fixed anchors as reference points. Artistic expressions always carry a sense of creativity and individuality from the performer, implying that performances can be different, but still deemed of the same quality. Making such distinctions requires additional experience and assessment practice.

The more realistic aspiration of young students would be an extension of their familiarity with key assessment criteria; however, such ambitions need to be realistic with a view to future growth. We believe getting to grips with the abstract concept of a standard is an example of such progression. D. Royce Sadler has written at length to explore this critical construct; however, concluded that the use of verbal statements to judge academic level is futile. He rather argues in favor of a holistic judgment, and sees this as the primary act, while justifications aim to proclaim the grounds for the appraisal. This approach still justifies the application of criteria; they are the means by which arguments become valid.

Criteria refer to features of any performance; however, are by themselves insufficient to decide levels of achievement. Sadler (2015) rather argues in favor of what he terms "triplets" to decide on critical grade bands, and in the use of a range of "instantiations", each consisting of one triplet composed of the actual performance (1), the assigned grade (2) and the justification (3). Sadler argues we need to give the abstract concept of a standard some material form as seen in the use of triplets. 


\section{Conclusion}

Vocal education draws on concepts beyond the vocabulary of everyday usage. In this study, the use of criteria as seen in an assessment rubric served as a gateway to essential features of vocal education. Its purpose was first to promote transparency, fairness and consistency in grading; however, the academy professors soon realized its potential for learning. Student active learning methods enjoy a lot of attention these days, and our project helped to facilitate the process without extensive costs and planning. Formative use of summative assessment criteria improved the design of the course by enabling constructive alignment, self-monitored and self-directed learning. Obvious gains were improved conceptual understanding among students combined with a power shift - from the professors to the students. They learned in groups and with peers, not just receiving instruction. Having said that, vocal education is a multifaceted and complex type of education in need of close collaboration between instructors and students. Becoming proficient in assessment and learning is a long-term project; however, academy professors are in a unique position to give it a smooth, yet solid beginning.

\section{References}

Davidson, J. W., \& Coimbra, D. (2001). Investigating performance evaluation by assessors of singers in a music college setting. Musicae Scientiae, 5(1), 33-53.

Gynnild, V. (2015). Assessing vocal performances using analytical assessment: a case study. Music Education Research, 1-15. doi:10.1080/14613808.2015.1025732

Kokotsaki, D., Davidson, J. W., \& Coimbra, D. (2001). Investigating the assessment of singers in a music college setting: the students' perspective. Research studies in music education, 16, 15-32.

Maugars, C. (2006). Attitudes of music teachers towards final examinations in the French music concervatoires. INternational Journal of Music Education, 24(1), 43-55.

Polanyi, M. (1958). Personal knowledge. London: Routledge and Kegan Paul.

Sadler, D. R. (1998). Letting students into the secret: Further steps in making criiteria and standards work to improve learning. Paper presented at the Board of Senior Secondary School Studies Conference of State and District Review Panel Chairs and Panellists, Bardon Professional Centre, Brisbane.

Sadler, D. R. (2009). Grade integrity and the representation of academic achievement. Studies in Higher Education, 34(7), 807 - 826.

Sadler, D. R. (2015). Assessment in Music Symposium. Retrieved from http://assessmentinmusic.com.au/about/dissemination/

Wapnick, J., \& Ekholm, E. (1997). Expert consensus in solo voice performance evaluation. Journal of Voice, 11(4), 429-436. doi:http://dx.doi.org/10.1016/S0892-1997(97)80039-2

Wenger, E. (2000). Communities of Practice and Social Learning Systems. Organization, 7(2), 225-246.

Zimmerman, B. J. (2002). Achieving self-regulation: the trial and triumpf of adolescence. In F. Pajares \& T. Urdan (Eds.), Academic motivation of adolescents. Greenich, CT: Information age Publishing. 